\title{
Map of self-perceived growth for reviewing user journey and negotiating career transitions
}

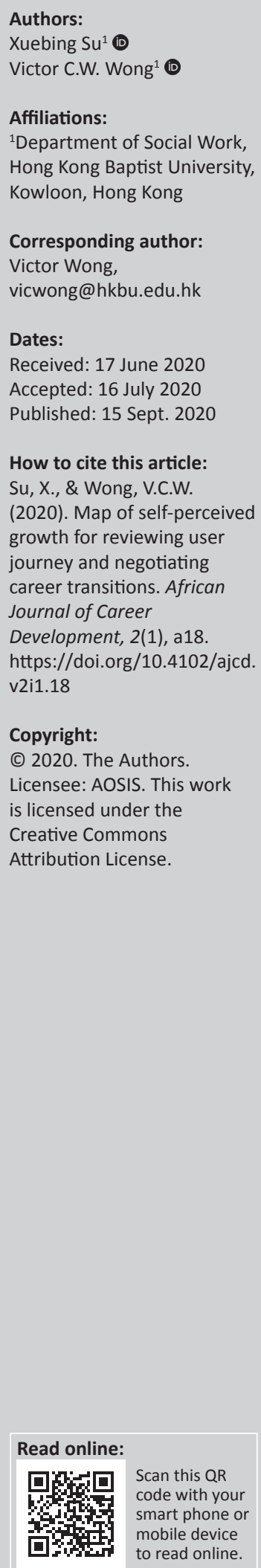

Background: There exist very few participatory research tools to facilitate youth to review and archive their user journey in a systematic manner for negotiating their career transitions.

Objective: The purpose of this study was to examine in what way the map of self-perceived growth (MSPG) was used as an effective participatory research tool for reviewing and archiving the user journey of marginalised youth for negotiating their career transitions and for drawing implications for career interventions and research.

Method: The MSPG template was used for conducting individual interviews with ex-users for mapping out their user journey with the use of nine emoji icons and a 10-point Likert-type scale. A thematic qualitative analysis was applied to study three sampled sets of transcripts and participant-constructed maps.

Results: The youth participants were able to map out their user journey with departure point, turning points and future career aspirations. The participant-constructed maps can visualise both psychological ownership and work volition and the use of psychosocial resources available from an enabling environment, which were found helpful for strengthening the agency of youth in negotiating career transitions, and showing embedded career interventions for drawing implications for both career interventions and research studies.

Conclusion: The study result suggests using the MSPG for reviewing and archiving user experience and articulating youth's career aspirations, which can help inform youth's negotiating career transitions. Further research studies on using the map template and the participant-constructed maps for strengthening agentic negotiations and career interventions are recommended.

Keywords: user journey; career transitions; youth agency; career interventions; participatory research.

\section{Introduction}

The term 'user journey' addresses the processes and experiences of service users as seen from the user perspective (Liu, 2019). Each user journey is characterised by a dynamic and interactive process positioned in between a starting or departure point and an end point of the entire course of service delivery. Therefore, user journey stories constructed by users or ex-users are able to show the embedded career interventions they went through and tell if the latter were effective in facilitating positive user change.

User journey constructed by users or ex-users may comprise a few dimensions, including plotting of user experiences, identification of feelings, facts and findings from user experiences, personal encounters with other people or significant others and emphasis on critical incidents associated with user changes and growth, etc. However, ex-users who had experienced a relatively longer rather than a transitional spell of status of not in education, employment or training (NEET) of 5 months or above (Su, Wong, \& To, 2020) may need a tool or a space to tell their user journey stories embodied with different relational, service and experiential encounters to consolidate their user experience. An archived map of user journey is considered helpful for acknowledging users' actions and abilities and relevant for generating sustainable impact, as it lasts longer than the use of the service itself (Farrell \& Nielsen, 2014). User journey stories used to reach insight into user experiences (Crosier \& Handford, 2012) can also help inform or improve the design of career support services as well.

User journey stories can be constructed through ongoing reviews or reflections conducted in a retrospective manner on an individual basis alone or on a one-to-one or small group basis 
facilitated by an interviewer (Allen, 2018). However, the conventional approach to conducting individual interviews tends to place youth participants in a relatively passive position (Karabanow, Kidd, Frederick, McLuckie, \& Quick, 2018), which has aroused a few major concerns as follows. First, interviewer-led interviews guided by a structured interview guideline tend to put youth participants in the position of answering questions in an inflexible manner. Semi-structured interviews can help but there is room to make further improvement for tapping personal experience outside the service scope and self-appraising one's growth experience during the service journey with some more facilitation. Second, the practitioners are not able to receive a copy of evaluation study report immediately after the interview. The time lag would end up preventing practitioners from taking prompt and appropriate actions to address the needs of their service users as necessary. Third, the participants would not be able to effectively learn about the mechanisms leading to their own individual learnings, changes and aspirations, as the findings and discussion shown in the research report are presented in an anonymous and collective manner apart from the aforementioned timelag problem.

\section{Exercise of youth agency in mapping out user journey}

An emerging trend taking place in participatory research is to emphasise the exercise of agency of youth participants in reviewing their own journey of growth and examining the favourable factors leading to their positive changes (Borda, 2006). The dialogue between the participant and the interviewer is informed by the guiding principle of 'leading from behind' (Savickas, 2005) with which the participant is treated as the focal person of the semi-structured interview as well as the storyteller of the user journey.

A core principle of participatory research is to provide young people with tools or frames to narrate and evaluate their life experience in the process of generation of knowledge (Borda, 2006). Prior studies have suggested some creative methods such as lifeline exercise, storytelling, drama and drawing to serve as constructivist tools to assist research participants to describe and reflect their experiences (Literat, 2013). These participatory research methods involving research participants have the advantages of: (1) lowering mere dependence on linguistic proficiency to narrate their experience, (2) introducing an entertaining component to make the research process more enjoyable and (3) cultivating a sense of ownership and contribution during the research process (Amsden \& VanWynsberghe, 2005; Literat, 2013). However, as participatory drawing relies primarily on visuals rather than texts, a valid interpretation of findings is arguably a significant concern. Against this backdrop, how to provide viable means to youth participants to facilitate their visualisation of their experiences, relations and learnings and yet give them room to narrate their own unique user journey is a real challenge.

\section{Map of self-perceived growth}

Informed by the expanded notion of work-values, attitudes, skills and knowledge (ENOW-VASK) framework (Wong \& Yip, 2019) with an emphasis placed on acknowledging users' untold or implicit VASK identified from their ENOW experiences, including a wide spectrum of paid and unpaid work activities (Wong, 2015), the first author developed the original map of self-perceived growth (MSPG) template and worked with the second author to fine-tune the template and write up a manual for interviewers to use this new participatory research tool. The MSPG was developed to visualise the experiences of youth participants and capture what they achieved over the user journey in terms of identifying their self-perceived growth, exploring the factors and mechanisms leading to positive changes and examining the effectiveness of career interventions.

By using the MSPG template during the individual interview and giving the participant the original copy of the hand-drawn map and the practitioner another copy for reference, it is possible to address the loopholes caused by the time-lag problem discussed here. Moreover, using both participant-constructed maps and interview transcripts is consistent with using methodological triangulation in qualitative research studies.

\section{Purpose of the study}

This study aims to examine in what way the MSPG template and the participant-constructed map were used as an effective participatory research tool for reviewing and archiving the user journey of marginalised youth with a prior status of NEET for enhancing their ability to negotiate career transitions ahead and discuss the implications for informing the practice of career practitioners and researchers.

\section{Methodology}

This study invited 26 ex-users of a career service project as research participants to attend an individual semi-structured interview and map out their self-perceived growth experiences, achievements, learnings and aspirations, which is titled Career and Life Adventure Planning Project for Youth (thereafter the project) funded by the Hong Kong Jockey Club Charities Trust. This 5-year long project launched in 2015 is targeted to youth aged 15-21 years who are NEET or NEET-at-risk. Amongst the 26 participants, 5 of them did not report their spell length as NEET, 5 of them were longer-term NEET ( $\geq 5$ months) and 16 were transitional NEET ( $<5$ months). Amongst the 21 participants who reported their spell length as NEET, 7 participants reported having special educational needs (SEN) amongst which one of them reported having other vulnerability as well, and 14 participants reported having no clear goals for career and life development. To cover a wider range of sociodemographic factors including spell length as NEET, that is, longer-term versus transitional NEET, single versus multiple vulnerabilities, and both genders, the study sampled 3 participants out of the 21 participants for this study: the first was a transitional NEET, the second was a longer-term NEET with multiple vulnerabilities and the third was a transitional NEET with SEN. 
Each interview including both conversations and mappingout in Cantonese, the mother tongue of the participants, lasted for about 2 hours. During the interviews, interviewers asked open-ended questions according to a semi-structured interview guideline. The participants were encouraged to share about their personal experiences within and beyond the service scope and evaluate their own growth experience during the user journey. At the end of each interview, the interviewer gave the original copy of the constructed map to the participant and asked for a consent from the latter to share a copy to his or her practitioner. This article adopted a qualitative method to examine interview transcripts and participant-constructed maps using a thematic analysis approach.

\section{Participants}

Table 1 presents the sociodemographic information of the three participants. To assure personal privacy and confidentiality, gender-specific pseudonyms are, respectively, assigned to the three participants as Elsa, Roger and Alex.

\section{Instruments}

The interviewers used a semi-structured interview guideline and a MSPG template to facilitate the participants to tell their user journey. The interviewers asked the participants openended questions including the following areas: (1) prior status and presenting concerns before using the service, (2) critical incidents and significant others or relationship they encountered and their growth and changes during the entire service journey they perceived, (3) current status and identity at the time of interview and finally (4) personal aspirations for future career and life development. An audio recorder was used to record the interviewing and mapping-out process. Some example interview questions are cited as follows: What were the problems you encountered at that time? During the user journey, anybody you met that changed your life? Were there any special moments that made yourself aware of your own changes? How do you describe your current status or identity? What are your long-term goals for your career and life development? Can you foresee your status or identity in 6 months, 9 months, a year or even longer?

The basic structure of the MSPG template is detailed as follows. First, the horizontal axis outlines the temporal dimension of participants' experience, their current status or identity and their career aspirations at the time of interview. Second, the vertical axis is a 10-point Likert-type scale from 1 to 10 , where 1 is of the lowest rating and 10 the highest.
Third, four Fs are used to denote facts, feelings, findings and futures (Greenaway, 1992) for reviewing their self-perceived growth in accordance with the 10-point Likert scale. Fourth, nine emoji icons including 'critical incident' (A),'significant others / relationship' (๕),'positive changes' (@),'negative changes' ( ), 'challenges' (圆), 'values/beliefs' ( $\bullet)$, 'attitudes' $(\bigcirc)$, 'skills' ( $)$ and 'knowledge' $(\square)$ are provided for the youth participants to elaborate and archive their achievements and learnings in every significant experience in a visual manner. Fifth, a curve to be drawn in the map represents the self-evaluation of the youth participants over the entire user journey. The ups and downs of the MSPG refer to the progression, regression and stable situation in relation to selfperceived growth. The interviewer prepared some tools for the drawing, including a pencil, an eraser, a ruler, a MSPG template with two axes and nine emoji icons for briefing the participants about the basic features of the map and another blank template with only two axes.

\section{Procedures}

Three interviewers including a researcher who was the first author and two other trained-up interviewers conducted the research interview with the three participants on a one-toone basis. Two other interviewers attended a training workshop provided by the project team before the interview. Prior to the study, the research team obtained ethical approval from the research ethics committee of the University where the authors work. After explaining the purpose and scope of the study to the participants, informed consent was collected from each of them prior to the commencement of the interview. All data collected were treated as confidential and only the research team could access the data.

\section{Data analysis}

To answer the question in what way the MSPG template and the participant-constructed maps work to help ex-users review and archive their user-journey stories for negotiating their career transitions ahead, three layers of data were used for this study: Layer 1 - data available from the transcripts; Layer 2 - data collected from the participant-constructed maps; and finally Layer 3 - notes taken by the researcher about the process of using the MSPG.

Thematic analysis of qualitative data was used to explore the themes and meanings embedded within the collected narratives and maps. Specifically, narrative analysis (Riessman, 2008) was used to understand participants' interpretation, visualisation and narration of user journey and any meanings and reflections assigned to their

TABLE 1: Sociodemographic information of the three participants.

\begin{tabular}{|c|c|c|c|c|c|c|}
\hline Participants & Gender & Age & Major problems encountered $\dagger$ & Initial educational attainment level & Spell length as NEET & Length of user journey \\
\hline Elsa & Female & 20 & No purpose in life & Secondary six & Transitional NEET (<5 months) & 2 years \\
\hline Roger & Male & 19 & $\begin{array}{l}\text { Youth with SEN (high functioning autism) and } \\
\text { social withdrawal experience }\end{array}$ & Secondary four & Longer-term NEET ( $\geq 5$ months) & 3 years \\
\hline Alex & Male & 17 & Youth with SEN (amblyopia) & Secondary six & Transitional NEET (<5 months) & 1.5 year \\
\hline
\end{tabular}

NEET, not in education, employment or training; SEN, special educational needs.

$\dagger$, As soon as the participants joined the project, they were invited to report the major problems encountered in relation to their career and life development; $\downarrow$, In Hong Kong, all students attend 6 years of secondary education including 3 years of junior secondary and 3 years of senior secondary education. 
experiences (Lam \& Chan, 2004). Qualitative data used for this study included the interview transcripts and the participant-constructed maps collected from the three sampled cases. All recordings were later transcribed into Chinese by the researcher. The transcripts and the participantconstructed maps were analysed in Chinese, rather than English, in order to better identify nuances in the language and to better represent the participants' lived experiences and perspectives.

Transcripts were read and reviewed by the authors who analysed the content of transcripts and identified the meaning units and themes embedded within the narratives and maps. Next, common or related meanings were categorised and grouped together to constitute an initial theme, which is a 'recurrent pattern of human intention' and make up 'the level of story concerned with what the characters in the narrative want and how they pursue their objective over time' (McAdams, 1993, p. 67). Related themes were then connected and compared. The structure of narratives was also examined (Riessman, 2008). In this study, with the aid of transcripts and participant-constructed maps characterised by a mix of selected icons and brief messages, plot development was identified by considering how the participants selected, connected and sequenced separate episodes of experience within and beyond the user journey (see Papathomas, Smith, \& Lavallee, 2015). In addition, the cultural resources and broader interpretive frameworks that the participants may have used to make sense of their user-journey experiences and self-constructed maps were also considered. Emergent themes and their potential connections were continuously reviewed in preparation for writing up the finalised themes to describe in the Findings section. Finally, representative verbatim quotes were labelled, translated into English and reviewed by the authors to ensure accuracy.

\section{Ethical consideration}

All procedures performed in studies involving human participants were in accordance with the ethical standards of the Research Ethics Committee of Hong Kong Baptist University and with the 1964 Helsinki declaration and its later amendments or comparable ethical standards. This article does not contain any studies with animals performed by any of the authors.

\section{Results}

Figure 1 presents the participant-constructed map of Elsa with original participant-written texts and translation in

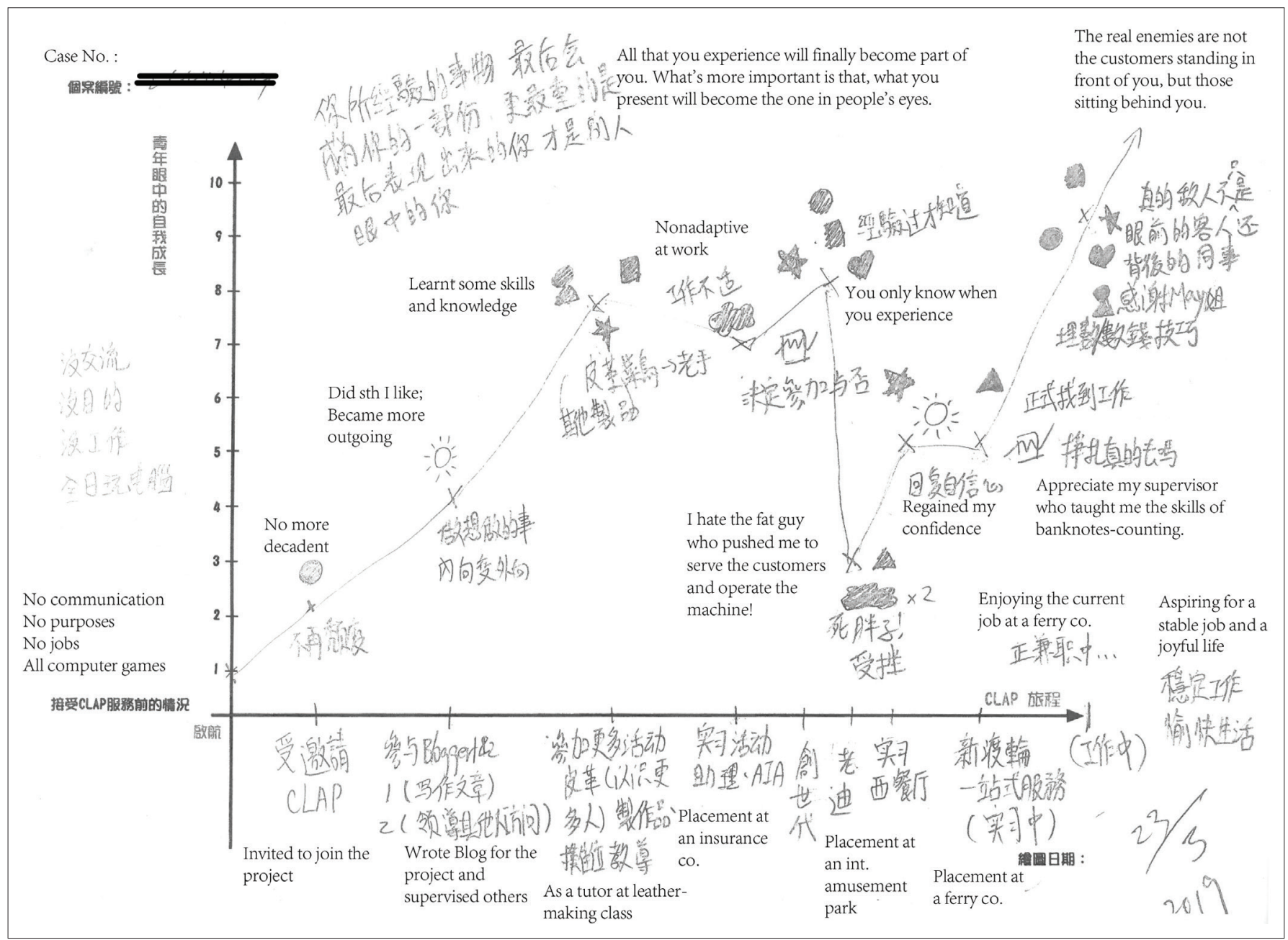

Note: The case number was covered for protecting the privacy of the participant.

FIGURE 1: A user journey mapped out by Elsa. 
English as a representative sample. A total of four themes were identified by analysing the three layers of qualitative data, which explained the mechanisms through which the MSPG template and the constructed map as a final product worked as an effective participatory research tool for reviewing and archiving the user journey of marginalised NEET youth for negotiating their career transitions.

\section{Theme 1: Applying a temporal dimension to review and archive user journey}

The participants started mapping out their user journey by recalling their prior disadvantaged status and presenting concerns in different yet similar expressions such as 'a lack of goals' (Alex, a transitional NEET with SEN), 'no purpose in life' (Elsa, a transitional NEET) and 'seclusion at home' (Roger, a longer-term NEET with multiple vulnerabilities) at the 'departure' point in the MSPG template before receiving career support service.

Using the temporal order of the story plot for reviewing, the participants were able to consolidate different types of experiences they went through during the user journey. The participants were guided to tell their user experiences from the first selected episode of user experience to the next one and then the last one they perceived important along the horizontal axis of the map. For example, Elsa recalled that she tried some interest classes at the beginning of her user journey: the first interest class that she joined was delivered by a blogger. It was about writing articles for the website on the project's blog with support from other service users, and the second one was a leather-making class run by an interestclass instructor who is a serious leisure devotee committed to the promotion and production of leather handicrafts.

Another major type of activities she had joined was a series of job placements highlighted in a sequential order over time. The placement as a receptionist at a social service centre came first; the placement at an insurance company came second; the placement at an amusement resort park was the third; the placement at a Western cuisine restaurant was the fourth; and the last one was at a ferry company.

After reviewing a series of career support services, participants' focus changed from the past to the present by marking their current status or identities in their maps. For example, Elsa marked her current status as 'enjoying the current job', and Alex marked 'studying a bachelor's degree programme in social work', whereas Roger used 'serious leisure devotee', 'employee' and 'social activist' to describe his current status or identities.

Based on the shared experiences and explicit current status or identity, the participants were well able to map out their career aspirations. Elsa aspired to keep working in the current ferry company with a sense of confidence and fulfilment through reviewing her participation in a series of activities with her social worker. Alex found his passion in music and expanding his horizon along the user journey, such as writing a proposal to apply for a youth award scheme to support his music programme, attending a semi-structured programme about animal caring, taking a job placement in a kitty café. Alex was thinking ahead of studying a short course in first aid during his undergraduate study and a diploma in music therapy after working for a few years as a social worker following the completion of the bachelor's degree programme in social work, which was about to start in a few weeks' time. All these endeavours planned in advance and to be pursued step by step can better equip him to serve teenagers and children with SEN in the long run. Regarding Roger's aspiration, his dream job was to become a district councillor, as he was fond of politics when he was very small, and even when he was trapped in self-seclusion at home for a protracted period of time. According to Roger's sharing, he was given a task that interested him to take photos for a floor curling competition in the first place, a role to form a playing team for a floor curling competition, and then a position as a coach for a series of floor curling competitions, and also a horizon-broadening chance to try out wheelchair escort service for wheelchair users who were either older people or people with a disability. All these activities appeared to help Roger experience success in working with his peers and teammates. Roger also had the opportunity to draw learnings 'to get rid of egocentricity, care for others and act for groupinterest' in his own words.

\section{Theme 2: Achieving a sense of psychological ownership towards user journey and career transitions}

The concept of psychological ownership emerged in psychological theories about people's territorial behaviours, which refers to the feelings held by individuals that they own a specific target (Avey, Avolio, Crossley, \& Luthans, 2009; Pierce \& Jussila, 2011). Individuals' psychological ownership towards a certain target will influence their attitudes and behaviours in relation to the target. Theories and empirical work suggest that people with a higher level of psychological ownership towards a target show a higher level of affective commitment for the target and act in a proactive manner to pursue positive outcomes for the target (Avey, Wernsing, \& Palanski, 2012; Bullock, 2015; Mustafa, Martin, \& Hughes, 2016; Peng \& Pierce, 2015). According to the ownership theory, there are three routes to foster the formulation of psychological ownership: experienced control over the target of ownership, intimate knowledge of the target and investment of self in the target (Pierce, Jussila, \& Cummings, 2009).

The MSPG template and the constructed map supported the participants to build up their psychological ownership towards their user journey and career transitions through establishing the aforementioned three routes to psychological ownership in the following ways. First, the participants were free to decide and select which experiences were significant to put up into their maps, to choose any wordings to describe their feelings, facts, findings, and/or futures in relation to their experiences and select any emoji icons to articulate their 
achievements and learnings from their experiences. Second, with the detailed briefing delivered by the interviewers, the participants were well informed about the purpose and components of the MSPG template. The questions raised by the interviewers facilitated the participants to recall their experiences in a thorough manner, and therefore, their intimate knowledge of their user journey was enhanced during the interview and mapping-out process. Third, the visualised participant-constructed map allowed the participants to acknowledge their own investment in each specific episode of experience in the user journey. Elsa used some emoji icons to describe her own performance in the ferry company: a circle to represent her serious attitudes for delivering customer service, a star to represent her professional skills as a ticket seller, a value icon to represent her value of caring for others and an icon of 'significant others' to represent a colleague that she modelled after for picking up the skills of banknote-counting. When Elsa recognised her own investment into her job at the ferry company, she felt fulfilling about her career transition. Alex witnessed his own improvement during his internship at the kitty café and recorded his positive changes with relevant emoji icons in his map:

'When people asked if I like this job or not, I would say "Yes!" I have done so much for this job and I can really make it! Other job placements that I tried were not my cup of tea. This is my job. I just love it. If possible, I would like to work longer a day to make more money from this job.' (Elsa, TN11, 23 March 2019)

'I didn't know how to complete tasks and what kind of attitudes I should maintain. I was uncertain what's going to happen. After all, I gradually became competent... Some of the customers talked to me nicely. I know how to handle the kittens, how to take orders and handle the floor works.' (Alex, TN03, 26 February 2019)

Finally, to foster the psychological ownership of the participant, the interviewers made a photocopy or took a photo of the participant-constructed maps and gave the original participant-constructed maps to the participants for their own record. The participants were suggested to revise their constructed maps on their own in the future as necessary.

\section{Theme 3: Visualising turning points and work volition}

The user journey shown in each of the participant-constructed maps was filled with ups and downs. A strong turning point from a lower score of self-perceived growth to a much higher score in particular was quite eye-catching in the participantconstructed maps. A strong turning point in participants' user journey is deemed important, as it can be interpreted as a practice of volition in their user journey, which has implications for negotiating their career transitions ahead. Work volition signifies a person's perceived capacity to make occupational choices despite constraints (Duffy et al., 2012). Elsa described her prior job placement experience at the amusement park before the strong turning point as a nightmare; however, she regained her confidence after going through the last placement at the ferry company.
Theoretically, when faced with the need for career adaptation, proactive individuals are likely to successfully prepare for and negotiate career-related changes when they are able to identify opportunities for improvement and create work environments that are congruent with their vocational needs (Bateman \& Crant, 1993; Seibert, Crant, \& Kraimer, 1999; Tolentino et al., 2014). Elsa showed her work volition in making up her decision to accept the job offer and take working in the ferry company as a pier assistant as an important platform for negotiating her career transitions ahead:

'I don't mind working in the early morning or working till late into the night. The supervisors are much nicer here. At least they will not force me to study English. They did teach me some taskrelated skills ... I watched them when they were handling a task and I listened. Then I learned a lot'. (Elsa, TN11, 23 March 2019)

Roger demonstrated his work volition by negotiating obstacles against pursuing his dream job as a district councillor. Not only did he learn about caring for others through joining various activities to craft his own character but also negotiate his pathway to get his dream job. As marked in his constructed map, he joined a political organisation and made use of his job at a canteen to practice his influence in the community, which were considered relevant to achieving his political and career aspirations. He even planned about becoming an assistant of a district councillor to realise his dream job one day:

'In this political organization, I am a member who focuses on transportation issues. I give opinions about transportation because I am a fan of buses. My opinions include but are not limited to bus lines, or issues about community planning. Through this political organization, I can influence the society. Moreover, my job at the canteen provided me opportunities to communicate with customers there, therefore I know about their needs and expectations about politicians.' (Roger, LTN02, 08 March 2019)

Alex's work volition was highlighted in his reflection about his failure to receive an award to attend a music programme he opted for. He still resolved to pursue his music dream through an alternative pathway in spite of acknowledging his own constraints:

'I did not do anything meaningful about music other than playing music and singing at home before joining the project. I have amblyopia and encountered difficulties of all kinds. However, by writing the proposal, I realized that there is a belief in the back of my mind: I want to bring music to others. I want to go to Taiwan to play street music and learn about the local musical culture.' (Alex, TN03, 26 February 2019)

\section{Theme 4: Emphasising the use and strengthening of psychosocial resources available from an enabling environment}

The idea of psychosocial resources denotes a person's resources to cope with contextualised tasks, transitions, challenges and traumas (Savickas \& Porfeli, 2012). Psychosocial resources held by an individual are not static traits but accumulated competencies gained through both education and experiences (Savickas \& Porfeli, 2012; Sullivan 
\& Sheffrin, 2003). However, young people who are deprived of formal education, training or working experiences as a result of a longer spell of NEET status are susceptible to the lack of psychosocial resources to cope with transitions, tasks and traumas encountered in their career and life development journey (Su et al., 2020).

The emphasis of the aforementioned ENOW-VASK framework is not only placed on the here-and-now context but also on the there-and-then context as long as young people are able to recall those adventurous, whether fruitful or less satisfying, memories where they can draw learnings from. All this is beneficial to help young people as ex-users to imagine the future and attempt to use their future aspirations to make sense of their present career-pathway mapping. Given the environment around is enabling and empowering enough, young people can re-read their experiences with their constructed map to strengthen their psychosocial resources.

The three participant-constructed maps were filled with emoji icons of VASK and positive changes. Elsa used a positivechange icon to represent her regaining confidence in the job placement in the ferry company. Alex used the icons of values, knowledge, skills and positive change to archive his learnings from the semi-structured programme about animal caring, including values of caring for others, knowledge about animal caring and animal food, communication skills and perceived holistic positive self-changes. Roger used the icons of VASK to describe his psychosocial resources developed from the wheelchair escort service:

'If we did not try to accompany the wheel chair users in daily life, we would never know they are having such an inconvenient life... For example, there is a strict standard for the gaps width of the drain covers, for the slope of ramp, and for pedestrians crossing, and handrails. I paid attention to these things, which would be strongly related to my dream of being a district councilor.' (Roger, LTN02, 08 March 2019)

The MSPG template and the constructed map itself encouraged the participants to archive their own psychosocial resources as well as the social support they gained from others during their user journey. For Elsa, her significant other was her supervisor in the ferry company, who had taught her some useful skills. Alex marked an icon of 'significant others' to represent his caseworker in every selected episode of experience. According to Alex, his caseworker had been playing an important role in influencing his career decision-making:

'I can feel the presence of my caseworker throughout all four stages of my growth experience in this project. He led me to the job placement at the café and supported me from Day $1 \ldots$ He has taught me how to handle various situations at work.' (Alex, TN03, 26 February 2019)

Upon receiving the public examination results, Alex found himself at the crossroads of making his own decision, which was different from his family's aspirations for him. After talking with his caseworker, he was able to tell his family his decision in taking the social work degree programme offered by a non-publicly funded tertiary institution rather than a non-social work degree programme offered by a publicly funded university.

\section{Discussion}

This study showed that the MSPG template and the final product of participant-constructed map were used as an effective participatory research tool for reviewing and archiving the user journey of disadvantaged youth through four interlocking mechanisms: (1) providing a temporal dimension for ex-users to review and archive their user journey and reach insight into their future career aspirations, (2) enhancing a sense of psychological ownership of participants towards user journey and career transitions ahead, (3) visualising turning points throughout user journey and work volition for negotiating future career transitions and (4) emphasising the use and strengthening of psychosocial resources available from an enabling environment for achieving career aspirations. After mapping out their user journey, the three participants were able to articulate their future directions for career pursuit and they appeared to draw an in-depth consolidation regarding their acquisition of psychosocial resources, which are helpful for strengthening their readiness and ability to negotiate career transitions and achieve career aspirations.

Each piece of participant-constructed map can be used as a means to strengthen individual agency for coping with career hurdles and negotiating career transitions through ongoing reflections on and continuing narration of preferred identities and actions with a good sense of career adaptability. The narration is neither a precise nor a truthful account of the life course itself but ongoing interpretation, reinterpretation and attribution of significance assigned to events and contexts that one subjectively finds important for the life course, the current situation and the ways to achieve aspirations (Illeris, 2017). Participants mapped out their life experiences, their subjective interpretations of their experiences and their own definition of their experience-driven identities in their constructed maps. Participants' constructed identities in the maps are coherent entities, which are not only reinterpreted in accordance with their reconstruction of experiences but also informed by their aspirations for future career and life development. Informed by the constructed identities, exusers are prepared to exercise agency and take proactive actions to negotiate their career transitions by taking futurecareer-informed actions.

According to the field notes of the researcher in this study, the caseworker of Roger asked the researcher for a copy of the map constructed by her ex-user, as she planned to hold a follow-up meeting with Roger in a week or two. This request was made possible after receiving consent from Roger. The maps constructed can thus support practitioners to deliver quality career support service in two possible ways: First, practitioners can seek permission from the participants for receiving a copy of their constructed maps for having a followup meeting with ex-users as necessary. Second, participants 
may take proactive actions instead to seek further guidance from their caseworkers by sharing with them their constructed maps. With the collection of participant-constructed maps, practitioners are able to develop insights into their career interventions so as to take relevant actions to work with service users with similar needs.

Although the participants of this study were all ex-users of a career support service, the MSPG template is considered applicable to current users as well as non-service users. With support from practitioners, current users can use the MSPG template to review and map out their user journey in relation to achievements and learnings so far and jot down their hopes and aspirations for the future. Career practitioners may discuss with their current users about the latter's constructed maps and draw insights for next-step interventions. By enjoying access to available MSPG user guideline and video clip, practitioners can map out their own professional journey by using the MSPG to review their professional practice on their own for consolidating practice wisdom, reaching practice insights and imagining practice possibilities.

Finally, the MSPG template and the constructed maps are shown as an effective tool for researchers to engage ex-users in participatory research for the sake of enhancing the agency of young people in the interviewing and mapping-out process. By using the MSPG, researchers are able to take up a bridging role between service users and their practitioners on the one hand and on the other hand enable the participants to share about their perceived growth experiences in a visualised manner and facilitate the practitioners to reflect on their career interventions for making further improvement.

However, there are some limitations of the present study. First, this study only examined the practice of using the MSPG with ex-users who were transitional or longer-term NEET youth. Future efforts are suggested to explore the use of the MSPG with other user groups such as adults or older people or nonservice users such as practitioners. Second, as three interviewers were involved in this study, it is not sure if there was any unintended personal influence on the participants during the interview process, which might lead to any bias for or against using the MSPG. Finally, this study is only focused on a thematic analysis of three ex-users' constructed maps and reflections of the researcher. Future research studies are recommended to examine the outcomes of using the MSPG for three interrelated parties, that is, participants, practitioners and researchers. For example, a longitudinal study is needed to investigate how career practitioners refer to the participantconstructed maps to review their interventions and support their service users. Moreover, more relevant studies are needed to examine the effectiveness of using the MSPG for other practitioner and user groups.

\section{Conclusion}

To conclude, this study demonstrated how to use the MSPG template and participant-constructed maps to help ex-users who were NEETs to review and archive their user journey in a career service project and revealed the mechanisms through which the MSPG template and the final product of participantconstructed map can function as an effective participatory research tool that is able to generate more sustainable impact for ongoing reviews and reflections. Implications for using the MSPG template and participant-constructed map for achieving both research and practice purposes were discussed in relation to three different yet interrelated stakeholders, that is, users, practitioners and researchers. Future practice of using the MSPG with different target groups is recommended, and further empirical research studies are needed to examine if these research and practice implications can be realised.

\section{Acknowledgements}

The authors would like to give special thanks to all the 26 participants for sharing their user journey stories and the funding support from the Hong Kong Jockey Club Charities Trust.

\section{Competing interests}

The authors declare that they have no financial or personal relationships that may have inappropriately influenced them in writing this article.

\section{Author's contributions}

The authors contributed equally to the writing up of the article.

\section{Funding information}

This work was supported by the Hong Kong Jockey Club Charities Trust (HKBU/HKJCCT/14-15/012).

\section{Data availability statement}

The data that support the findings of this study are available from the corresponding author upon reasonable request.

\section{Disclaimer}

The authors declare that the views expressed in the submitted article are their own and not an official position of the institution or funder.

\section{References}

Allen, K.L. (2018). Hubble, bubble, toil and trouble: Meddling in mental health services using participatory action research, Doctoral dissertation, University of Central Lancashire.

Amsden, J., \& VanWynsberghe, R. (2005) Community mapping as a research tool with youth. Action Research, 3(4), 357-381. https://doi.org/10.1177/1476750305058487

Avey, J.B., Avolio, B.J., Crossley, C.D., \& Luthans, F. (2009). Psychological ownership: Theoretical extensions, measurement and relation to work outcomes. Journal of Organizational Behavior, 30(2), 173-191. https://doi.org/10.1002/job.583

Avey, J.B., Wernsing, T.S., \& Palanski, M.E. (2012). Exploring the process of ethical leadership: The mediating role of employee voice and psychological ownership. Journal of Business Ethics, 107(1), 21-34. https://doi.org/10.1007/s10551-012 1298-2

Bateman, T.S., \& Crant, M.J. (1993). The proactive component of organizational behavior: A measure and correlates. Journal of Organizational Behavior, 14(2), 103-118. https://doi.org/10.1002/job.4030140202 
Borda, O.F. (2006). Participatory (action) research in social theory: Origins and challenges. In P. Reason \& H. Bradbury (Eds.), Handbook of action research: Participative inquiry and practice (pp. 27-37). London: Sage.

Bullock, R.B. (2015). The development of job-based psychological ownership, Doctoral Dissertation, Seattle Pacific University.

Crosier, A., \& Handford, A. (2012). Customer journey mapping as an advocacy tool for disabled people: A case study. Social Marketing Quarterly, 18(1), 67-76. https:// doi.org/10.1177/1524500411435483

Duffy, R.D., Diemer, M.A., Perry, J.C., Laurenzi, C., \& Torrey, C.L. (2012). The construction and initial validation of the Work Volition Scale. Journal of Vocationa Behavior, 80(2), 400-411. https://doi.org/10.1016/j.jvb.2011.04.002

Farrell, S., \& Nielsen, J. (2014). User experience careers. Nielsen Norman Group, Fremont.

Greenaway, R. (1992). Doing reviewing. Journal of Adventure Education and Outdoor Leadership, 9(1), 15-17.

Illeris, K. (2017). How we learn: Learning and non-learning in school and beyond. Routledge, London. https://doi.org/10.4324/9781315537382

Karabanow, J., Kidd, S., Frederick, T., McLuckie, A., \& Quick, J. (2018). Methodological reflections on research with street youth. Journal of Social Work, 18(5), 578-597. https://doi.org/10.1177/1468017316656145

Lam, M.C. \& Chan T. S. (2004). Life themes in the narratives of young Chinese immigrants who have successfully adjusted to life in Hong Kong. Journal of Youth Studies, 7(4), 433-449. https://doi.org/10.1080/1367626042000315211

Literat, I. (2013). 'A pencil for your thoughts': Participatory drawing as a visual research method with children and youth. International Journal of Qualitative Methods, 12(1), 84-98. https://doi.org/10.1177/160940691301200143

Liu, Y. (2019). Exploring the application of inclusive design to the improvement of healthcare services, Doctoral dissertation, University of Cambridge.

McAdams, D.P. (1993). The stories we live by: Personal myths and the making of the self. New York, NY: Guilford Press.

Mustafa, M., Martin, L., \& Hughes, M. (2016). Psychological ownership, job satisfaction, and middle manager entrepreneurial behavior. Journal of Leadership \& Organizational Studies, 23(3), 272-287. https://doi.org/10.1177/154805181 5627360

Papathomas, A., Smith, B., \& Lavallee, D. (2015). Family experiences of living with an eating disorder: A narrative analysis. Journal of Health Psychology, 20(3), 313-325. https://doi.org/10.1177/1359105314566608
Peng, H., \& Pierce, J. (2015). Job-and organization-based psychological ownership: Relationship and outcomes. Journal of Managerial Psychology, 30(2), 151-168. https://doi.org/10.1108/JMP-07-2012-0201

Pierce, J.L., \& Jussila, I. (2011). Psychological ownership and the organizational context: Theory, research evidence, and application. Edward Elgar Publishing, Cheltenham.

Pierce, J.L., Jussila, I., \& Cummings, A. (2009). Psychological ownership within the job design context: Revision of the job characteristics model. Journal of Organizational Behavior: The International Journal of Industrial, Occupational and Organizational Psychology and Behavior, 30(4), 477-496. https://doi. org $/ 10.4337 / 9780857934451$

Riessman, C.K. (2008). Narrative methods for the human sciences. Los Angeles, CA: Sage.

Savickas, M.L. (2005). The theory and practice of career construction. Career development and counseling: Putting theory and research to work (pp. 42-70) New Jersey: John Wiley \& Sons, Inc.

Savickas, M.L., \& Porfeli, E.J. (2012). Career Adapt-Abilities Scale: Construction, reliability, and measurement equivalence across 13 countries. Journal of Vocational Behavior, 80(3), 661-673. https://doi.org/10.1016/j.jvb.2012.01.011

Seibert, S.E., Crant, J.M., \& Kraimer, M.L. (1999). Proactive personality and career success. Journal of Applied Psychology, 84(3), 416-427. https://doi.org/ 10.1037/0021-9010.84.3.416

Su, X., Wong, V., \& To, S.M. (2020). Factor structure of the Chinese Career AdaptAbilities Scale in youth with a longer spell of status of not in education, employment, or training. Child \& Youth Service, 41, 1-18. https://doi.org/10.1080 /0145935X.2020.1768843

Sullivan, A., \& Sheffrin, S.M. (2003). Economics: Principles in action. Upper Saddle River, NJ: Pearson Prentice Hall.

Tolentino, L.R., Garcia, P.R.J.M., Lu, V.N., Restubog, S.L.D., Bordia, P., \& Plewa, C. (2014). Career adaptation: The relation of adaptability to goal orientation, proactive personality, and career optimism. Journal of Vocational Behavior, 84(1), 39-48. https://doi.org/10.1016/j.jvb.2013.11.004

Wong, V. (2015). Youth transition to work in an age of uncertainty and insecurity: Towards an expanded notion of work for insight and innovation. Journal of Applied Youth Studies, 1(1), 21-41

Wong, V. \& Yip, T.C.B. (2019). 'Promoting change' The 'Expanded Notion of Work' as a proactive response to the social justice issues in career development practice. In T. Hooley, R.G. Sultana \& R. Thomsen (Eds.), Career guidance for emancipation: Reclaiming justice for the multitude (pp. 64-80). London: Routledge. 